\title{
Bolted Connection of an End-Plate Cantilever Beam: The Distribution of Operating Force
}

\author{
Simon Oman $1,{ }^{*}$ - Marko Nagode \\ University of Ljubljana, Faculty of Mechanical Engineering, Slovenia
}

This paper presents an alternative method for calculating the operating forces on bolts in the bolted connections of the end-plate cantilever beams. Since operating force reduces pressure between the joined surfaces the influence of the operating force needs to be considered when determining the clamping force. Therefore, correctly defined operational force on each bolt is a base for all further calculations.

To evaluate proposed method, results of four existing analytical methods for calculating the operating forces in the bolted connections of the end-plate cantilever beams are compared with the results of the alternative method and the results gained by finite element analyses. Because finite element analysis take into account all influential parameters it is expected that the results obtained by finite element analyses are a good approximation to reality and can serve as a reference when comparing different analytical methods. It turns out that the results of the proposed method coincide with the results of finite element analyses the most. Only the proposed method correctly determines which bolts in the connection are subjected to the highest additional loads.

Keywords: bolted connection; endplate connection; operating force; bolt pretension; structural steel; finite element method

Highlights
- $\quad$ New method for calculating the distribution of operating forces on bolts is presented.
- $\quad$ Results gained by presented method coincide with the FEM analysis the most.
- $\quad$ The method, in contrast to existing analytical methods, correctly determines the most critical bolts for selected cases.

\section{O INTRODUCTION}

Bolted connections of beams are very common joints in steel constructions. There are two basic bolted joint types that an engineer can use to connect two parts together: snug tight and prestressed joint. The two differences between these joints are the amount of mounting force achieved during installation, and the allowable movement between those surfaces in contact while in service. Since most steel constructions are dynamically loaded, prestressed joints are commonly used. In a prestressed joint, pressure between surfaces in contact and a coefficient of friction form a frictional force that prevents slippage. If no slippage is allowed, the frictional force in the worst load case has to be greater than a tangential force (i.e. a force occurring in a direction parallel to the joint surfaces) that appears as an outside load during operation. This is achieved by the proper determination of the clamping force (i.e. the mounting force of each bolt). For many prestressed joints a force component normal to the joint surfaces, the operating force, acts in addition to the tangential force (the operating force also being coincident with the axial direction of the bolts). This operating force reduces the pressure between the joined surfaces and hence reduces the sealing force [1] to [3] where the sealing force is the product of the pressure and the effective cross section. Consequently, the frictional force is also reduced. Therefore the influence of the operating force needs to be considered when determining the clamping force [4]. For the endplate cantilever beam discussed in this article (see Fig. 1), the joint is loaded with a tangential force and a normal force due to an applied bending moment. The difficulty in determining the necessary clamping force to prevent slippage occurs when estimating the distribution of the operating force across the bolts. The value of the operating force on each bolt is in fact dependent on many factors, particularly its location within the joint.

In practice several different analytical methods are currently used for calculating the operating forces in the bolted connections of the end-plate cantilever beams. All these methods are based on various assumptions, leading to diverse results. These methods are fundamentally different with respect to the assumed position of the neutral axis, which defines which bolts in the junction are more or less loaded due to the operating force. The first analytical method [5] is the simplest since it assumes that the neutral axis is located in the middle of the flange. It should be noted at this point that this method is appropriate only for flange connections of I-beams. The second method [6] sets the neutral axis at the lower edge of the flange and thus assumes all bolts are additionally loaded. The third method [7] assumes that the neutral 
axis is positioned at a quarter of the flange height. The fourth method [8] sets the position of the neutral axis based on the thickness of the flange. It turns out that the fourth method [8] is the most accurate of the four, but even with this method the results may differ considerably from reality. With regard to the operating force the first method assumes it is equally distributed across the bolts above the neutral axis. The other three methods assume a linear distribution of the operating force across the bolts according to the distance from the neutral axis. Such a distribution would be possible only if the flange is absolutely rigid which in practice is simply not feasible. Therefore, we can conclude that these methods are very approximate and only the latter takes into account an additional parameter (the thickness of the flange) to determine the neutral axis position. However, we know that the actual distribution of the operating force across the bolts is mostly dependent on the bending stiffness of the flange, which is not constant due to the spot attachment via the bolts. Hence an alternative analytical method is presented here which accounts for this distribution of the operating force across the bolts.

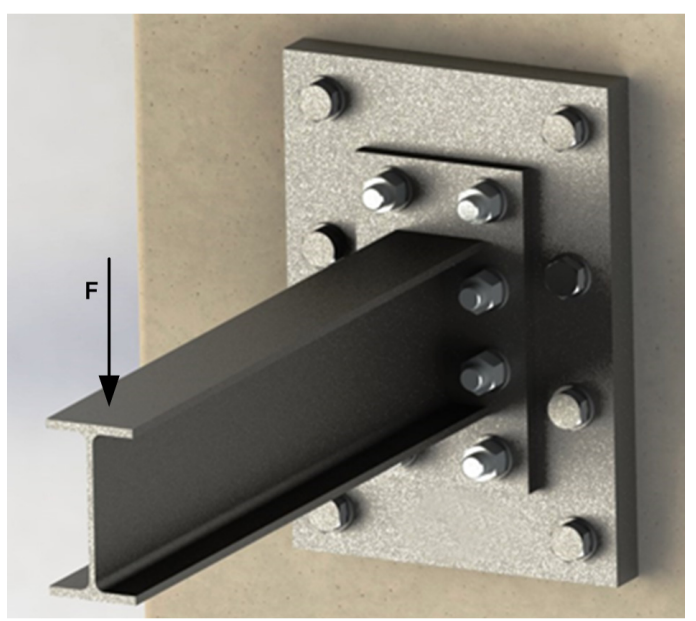

Fig. 1. Bolted connection of the end-plate cantilever beam

\section{METHOD FOR CALCULATING THE OPERATING FORCE ON BOLTS}

The idea of the method is as follows. First normal stresses in the beam at the connection with the flange (see Fig. 2) due to the applied bending moment are calculated. The bending moment is calculated using the equation:

$$
M=F \cdot r,
$$

where $M$ is the bending moment at the beam-flange connection, $F$ is the operating load in a tangential direction and $r$ is the distance from the end of the beam to the point where the operating force is applied.

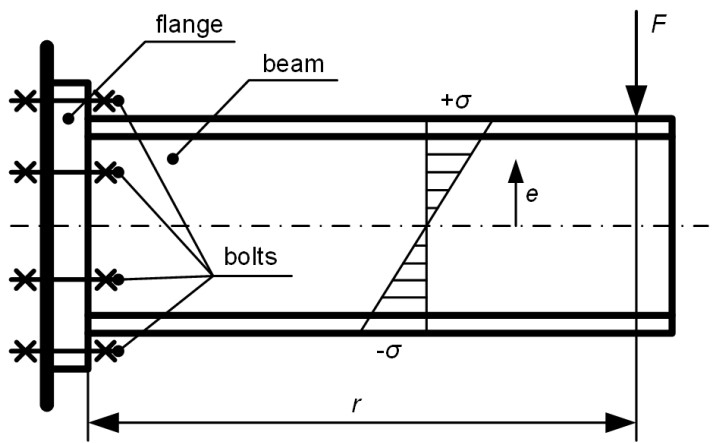

Fig. 2. Sketch of the end-plate cantilever beam

Theoretically normal stresses change from tension on one side of the beam to compression on the other, whilst remaining zero on the neutral axis. The stresses are calculated using the equation:

$$
\sigma=\frac{M \cdot e}{I}
$$

where $e$ is the distance from the neutral axis to the position of interest and $I$ is the moment of inertia of the cross-section of the beam. In the next step, the normal stresses are converted into the total normal force separately for the tension and compression regions of the section. The total normal force is calculated using the equation:

$$
F_{N}=\int_{0}^{e_{\max }} \frac{M \cdot e}{I} \cdot t \cdot d e
$$

where $e_{\max }$ is the distance from the neutral axis to the edge of the cross-section and $t$ is the thickness of the cross-section. If the thickness of the cross-section is not constant, as is the case for an I-beam, Eq. (3) must be written separately for each thickness. The equation for calculating the total normal force in the case of an I-beam would be as follows:

$$
\begin{aligned}
& F_{N}=\int_{0}^{e_{1}} \frac{M \cdot e}{I} \cdot t_{1} \cdot d e+ \\
& +\int_{e_{1}}^{e_{2}} \frac{M \cdot e}{I} \cdot\left(2 \cdot r+t_{1}-2 \cdot \sqrt{r^{2}-\left(e-e_{1}\right)^{2}}\right) \cdot d e+ \\
& +\int_{e_{2}}^{e_{\max }} \frac{M \cdot e}{I} \cdot t_{2} \cdot d e
\end{aligned}
$$

where $t_{1}$ is the thickness of the beam web, $t_{2}$ the width of the beam flange and $r$ is the radius on the web- 
flange connection. Further, the location of application of the total normal force has to be calculated separately for the tension and compression regions. The point of force application is calculated using the following equation:

$$
M_{R}=F_{N} \cdot y \rightarrow y=\frac{M_{R}}{F_{N}}
$$

where $y$ is the distance from the neutral axis to the point of the force application and $M_{R}$ is the moment of one of the regions (tension or compression) calculated using the following equation:

$$
M_{R}=\int_{0}^{e_{\max }} \frac{M \cdot e^{2}}{I} \cdot t \cdot d e
$$

Once again the equation for calculation of moment needs to be applied separately to each section if the thickness of the cross-section is not constant. Knowing the values and the points of application of the total normal forces that actually represent the outside loads on the flange (see Fig. 3) the operating force on the bolts can be calculated. In the next step of the method it is assumed that the total tension force is distributed only across those bolts among which it is located. For the example shown in Fig. 3 this means the total tension force is distributed across the upper four bolts. It is further assumed that the distribution of the operating force across these four bolts depends on its vertical distance from the total normal force application point. For the example in Fig. 3 the operating force for the first line of the bolts can be calculated using the equation:

$$
F_{O 1}=\left(F_{N} \cdot \frac{a}{a+b}\right) / n_{1},
$$

where $F_{O I}$ is the operational force on one bolt in the first line, $a$ and $b$ are distances of the bolt's location from the point of application of the total normal force (see Fig. 3), and $n_{1}$ the number of bolts in the first line. For the second line the equation is as follows:

$$
F_{O 2}=\left(F_{N} \cdot \frac{b}{a+b}\right) / n_{2} .
$$

Furthermore it is assumed that the total compression force is distributed across the remaining bolts. In Fig. 3 this means the total compression force is distributed across the lower four bolts. For compression, the normal force is transferred through the flange directly to that surface which the flange is connected to. Therefore the bolts are not additionally loaded but are relieved by an amount corresponding to the deformation (flattening) of the flange at the location of the bolt. Since bolts are

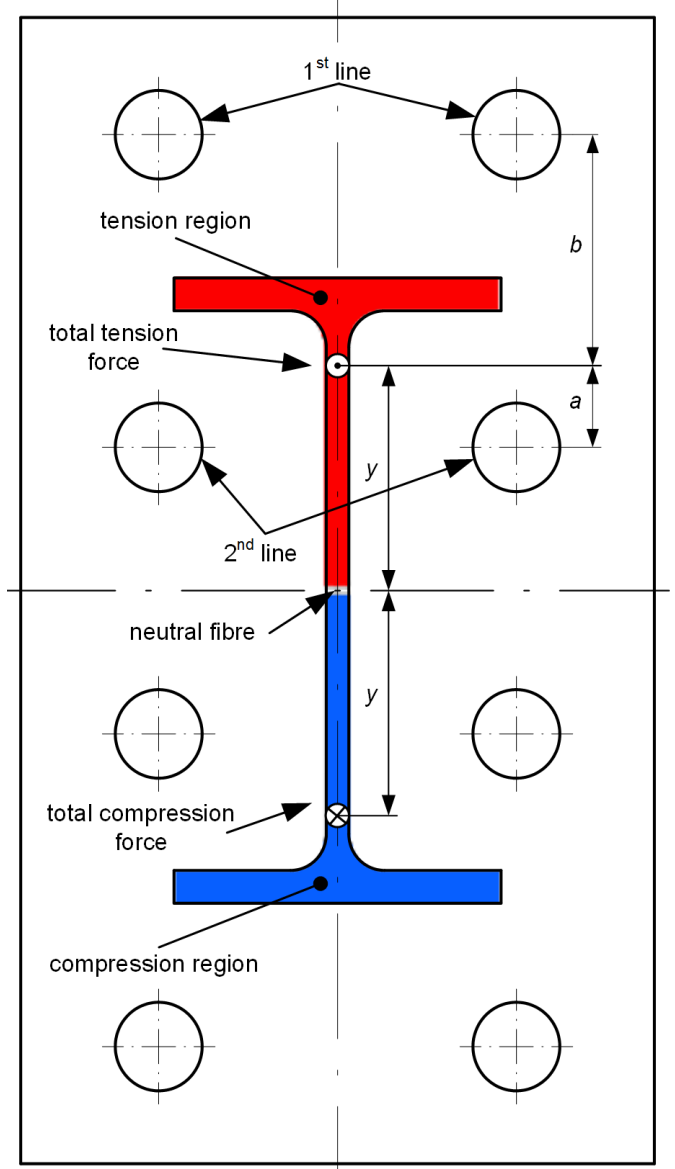

Fig. 3. Sketch of the normal forces acting on the flange

usually located more than one bolt diameter from the nearest point of the beam cross-section and the fact that the compression stiffness of the flange is high, the deformation of the flange around bolts located in the compression region is negligible. Consequently, the difference in total bolt load for all bolts in the compression region is also negligible. Therefore our method assumes that the clamping and thus the sealing force of the bolts in the compression zone does not change despite the action of the operational force, hence the initial prestressed state can be considered for all further calculations. The assumption that the total normal force is distributed only across those bolts among which it is located holds when the stiffness of the bolts compared to the bending stiffness of the flange is much higher. In this case the clamping force is selected so that, despite the action of the operational force, the surfaces in the bolt region remain in contact. Since the bolted connection of the end-plate cantilever beam is usually designed so as to prevent slippage the above mentioned conditions are normally fulfilled 
and our assumptions are acceptable. The method here assumes that the neutral axis of the beam is located at the centre of mass of the beam cross-section. However, due to differences in bending stiffness of the flange in the tension and compression regions the neutral axis is shifted towards the total compression force. The reason for this is that in the compression region deformation of the flange is restrained over the whole surface by the surface to which it is fixed, whilst in the tension region the flange is restrained locally by the bolts. As a consequence the value and location of the total tension and compression forces also change. The neutral axis is located at the centre of mass only for cases where the flange is totally rigid which in reality is not possible. Therefore the neutral axis location is always slightly shifted. The value of this shift depends on numerous parameters such as the location of the bolts, flange thickness, flange material, the value of the clamping force and dimensions of the bolts, etc. To incorporate all of these parameters into a calculation would be a very demanding task that would not alter the results significantly as the shift of the neutral axis would be relatively small. Hence the proposed method, despite the assumption that the neutral axis is located at the centre of mass of the beam cross-section, gives better results than previous methods, as discussed in Section 3.

\section{SIMULATION OF AN END-PLATE CANTILEVER BEAM BY THE FINITE ELEMENT METHOD}

The stress strain state of the flange and bolts in the bolted connection of the end-plate cantilever beam is very hard to determine. Therefore, it is practically impossible to take into account all the influential parameters when calculating the distribution of the operating force across the bolts using an analytical model. However using the finite element (FE) method all such parameters can be taken into account. For this reason, in past years, finite element models [9] to [14] have been largely applied to simulate structural elements and structures. Therefore it is expected that the results obtained by finite element analysis are a good approximation to reality and will serve as a reference when comparing the new analytical method with previous methods of calculation. All finite element analyses are performed using ABAQUS software.

\subsection{Finite Element Model}

To determine the distribution of the operating force across the bolts, the end-plate cantilever beam FE model (see Fig. 4) is composed of several parts: beam, flange, support plate, bolts, nuts and washers.

Plastic material properties are used to define the material characteristics of all the parts. For the beam, flange and support plate, construction steel S235 properties are used; for bolts, nuts and washers a quality of 10.9 with a yield strength of $900 \mathrm{~N} / \mathrm{mm}^{2}$ is assumed. The beam and the flange are connected together using a tie connection property. The flange is connected to the support plate by the prestressed bolts. Flange - support plate, support plate - washer and washer - nut contacts are simulated using frictional contacts with a coefficient of friction of 0.2. Bolt nut and bolt - support plate connections are simulated as tie connections. In the first step of the analysis the
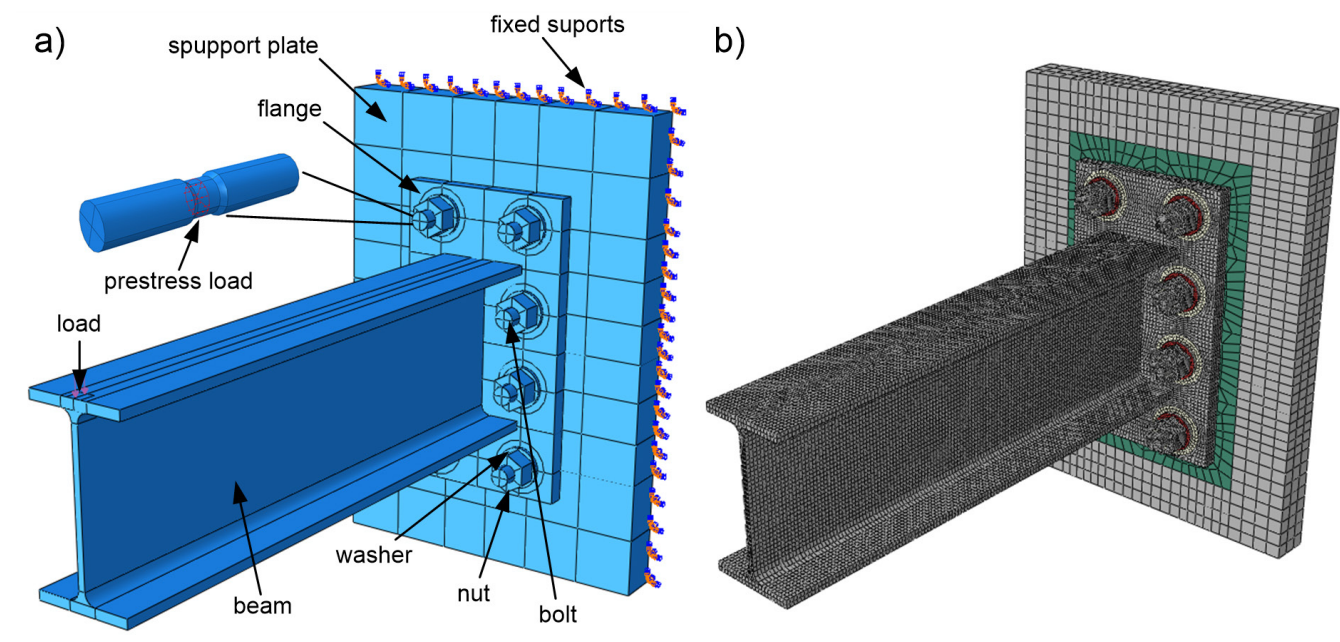

Fig. 4. Finite element model: a) parts, and b) mesh 
prestress is applied to each bolt using the bolt load property. The value of the prestress is defined in such a way that prevents sliding between the connected surfaces, in this case $32 \mathrm{kN}$. In the second step, a $10 \mathrm{kN}$ load is applied to the end of the beam in the vertical direction. The result of the analysis gives the additional load at each bolt. Since the bolted connection is a connection of two elastic elements the total operating force on the connection is divided into two parts. The first is the additional load on the bolt and the second is the relief of the flange. The value of each part depends on the ratio of the bolt and flange elasticity and a load application factor (see Fig. 5).

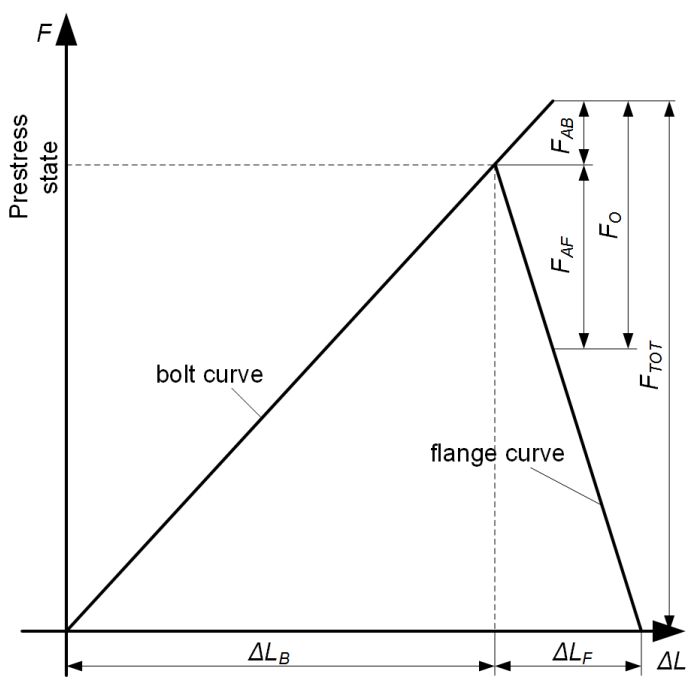

Fig. 5. Diagram of prestressed bolt joint ( $F_{O}$ operating force, $F_{A B}$ additional bolt load, $F_{A F}$ relief of the flange, $F_{\text {TOT }}$ total or maximum bolt load, $\Delta L_{B}$ bolt deformation at prestress state, $\Delta L_{F}$ flange deformation at prestress state)

Assuming that the operating load is applied directly to the bolt head or nut, which means that the load application factor is 1 , the total operating force can be calculated from the additional bolt load using the following equation [15]:

$$
F_{O}=F_{A B} \cdot \frac{\delta_{B}+\delta_{F}}{\delta_{F}},
$$

where $F_{A B}$ is the additional bolt load, $\delta_{B}$ bolt elasticity and $\delta_{F}$ flange elasticity. Bolt and flange elasticity can be calculated using Eqs. (10) to (11) [15].

$$
\begin{aligned}
\delta_{B} & =\sum_{i=1}^{n} \delta_{i}+\delta_{T}+\delta_{U}+\delta_{H}+\delta_{N}= \\
& =\frac{1}{E_{B}} \sum_{i=1}^{n} \frac{l_{i}}{A_{i}}+\frac{l_{T}}{A_{T}}+\frac{l_{U}}{A_{3}}+\frac{l_{H}+l_{N}}{A_{d}},
\end{aligned}
$$

$$
\delta_{F}=\frac{2 \cdot \ln \left[\frac{\left(d_{w}+d_{h}\right) \cdot\left(d_{w}+w \cdot l_{k} \cdot \tan \varphi-d_{h}\right)}{\left(d_{w}-d_{h}\right) \cdot\left(d_{w}+w \cdot l_{k} \cdot \tan \varphi+d_{h}\right)}\right]}{w \cdot E_{F} \cdot \pi \cdot d_{h} \cdot \tan \varphi},
$$

$\delta_{i} \quad[\mathrm{~mm} / \mathrm{N}]$ Elasticity of those parts of the bolt with a constant cross-section $A_{i}$

$\delta_{T} \quad[\mathrm{~mm} / \mathrm{N}]$ Elasticity of the threaded part of the bolt

$\delta_{U} \quad[\mathrm{~mm} / \mathrm{N}]$ Elasticity of the co-operating part of the bolt screwed into the nut

$\delta_{H} \quad[\mathrm{~mm} / \mathrm{N}]$ Elasticity of the co-operating part of the bolt head

$\delta_{N} \quad[\mathrm{~mm} / \mathrm{N}]$ Elasticity of the co-operating part of the nut

$E_{B} \quad[\mathrm{MPa}]$ Young's modulus of the bolt

$l_{i} \quad[\mathrm{~mm}] \quad$ Length of those parts of the bolt with a constant cross-section $A_{i}$

$l_{T} \quad[\mathrm{~mm}] \quad$ Length of the threaded part of the bolt between the bolt head and the nut

$l_{U} \quad[\mathrm{~mm}] \quad$ Length of the co-operating part of the bolt screwed into the nut

$l_{H} \quad[\mathrm{~mm}] \quad$ Length of the co-operating part of the bolt head

$l_{N} \quad[\mathrm{~mm}] \quad$ Length of the co-operating part of the nut

$A_{T} \quad\left[\mathrm{~mm}^{2}\right] \quad$ Supporting cross-section of the thread

$A_{3} \quad\left[\mathrm{~mm}^{2}\right] \quad$ Size of the bolt thread core screwed into the nut

$A_{d} \quad\left[\mathrm{~mm}^{2}\right] \quad$ Nominal cross-section of the bolt

$d_{w}[\mathrm{~mm}]$ Diameter of the bolt resting on the surface of the flange

$d_{h} \quad[\mathrm{~mm}] \quad$ Diameter of the hole

$w \quad[/] \quad$ Factor of the bolted connection type (here $w=2$ )

$l_{k} \quad[\mathrm{~mm}] \quad$ Thickness of the flange

$\varphi \quad\left[{ }^{\circ}\right] \quad$ Angle of the pressure cone under the bolt head

$E_{F} \quad[\mathrm{MPa}]$ Young's modulus of the flange material

In order to facilitate the comparison of the results of FEM analyses with analytical methods, the results of the additional bolt load obtained by FEM analyses are converted into the operational force using Eq. (9) taking into account the elasticity of the bolts and flanges from Table 1.

Table 1. Bolts and flanges elasticity

\begin{tabular}{lcc}
\hline Thickness of the flange $l_{k}[\mathrm{~mm}]$ & 12 & 20 \\
\hline$\delta_{B}[\mathrm{~mm} / \mathrm{N}]$ & $1.5243 \cdot 10^{-6}$ & $8.7479 \cdot 10^{-8}$ \\
\hline$\delta_{F}[\mathrm{~mm} / \mathrm{N}]$ & $1.7675 \cdot 10^{-6}$ & $1.2353 \cdot 10^{-7}$ \\
\hline
\end{tabular}




\subsection{Finite Element Results}

Finite element analyses of four combinations of beam shape and flange thickness were carried out. The results show that both parameters (beam shape and flange thickness) have an influence on the distribution of the operational force across the bolts.

This then means they also influence the location of the neutral axis that divides the tension and compression parts of the contact area between the beam and the flange. Theoretically the neutral axis is located at the centre of mass of the beam cross section, but this is only true when the flange on which the beam is connected to is rigid. In reality the neutral axis is moved towards the compression region due to differences in bending stiffness of the flange in regions of tension and compression (see Fig. 6a). The analyses also show that for an appropriate clamping force (i.e. the clamping force is sufficient to prevent slippage but not so high as to prevent plastic deformation of the bolts) there is no gap between the flange and the support plate around the bolts despite the application of the operating force (see Figs. $6 b$ and $c$ ). Therefore only bolts in the tension region can be additionally loaded. From the deformation of the flange (see Figs. $6 \mathrm{~b}$ and $\mathrm{c}$ ) it is obvious that the bending stiffness of the flange is much smaller than the tensional stiffness of the bolts which is the main reason why the total operational force is distributed only across the bolts in the tension region. As said before, a linear distribution of the operational force across the bolts would only be possible if a very stiff flange were used. Because of relatively large deformations of the flange (see Fig. $6 b)$ the actual load on the affected bolts is not purely tensional but a combination of tension and bending. Therefore the distribution of the axial stress in the bolt cross-section is not symmetrical which is clearly visible in Fig. 7.

\section{RESULTS AND DISCUSION}

The four existing analytical methods [5] to [8] presented in the introduction are compared to both the method presented in this paper and the FE analyses described in the previous section. The methods have been applied to four samples wherein the thickness of the flange and the shape of the beam are the changing parameters. The thickness of the flange is either $12 \mathrm{~mm}$ or $20 \mathrm{~mm}$ and either an IPE 120-beam or a custom T-beam is used. The dimensions of the flange, bolt positions and beam dimensions are shown in Fig. 8. The point of application of the vertical force is the same for all cases (400 $\mathrm{mm}$ from the support plate). To fix the beam to the support plate, specialised M16 bolts are used.

\subsection{Comparison of Results}

The results for each analytical method together with the FE analysis are shown in Table 2 and Fig. 9. Since the first method [5] is intended solely for flange joints of I-beams, the data for T-beam joints are not presented in the table. The results deviate quite a lot from each other. If the FE analysis is considered as a reference, it

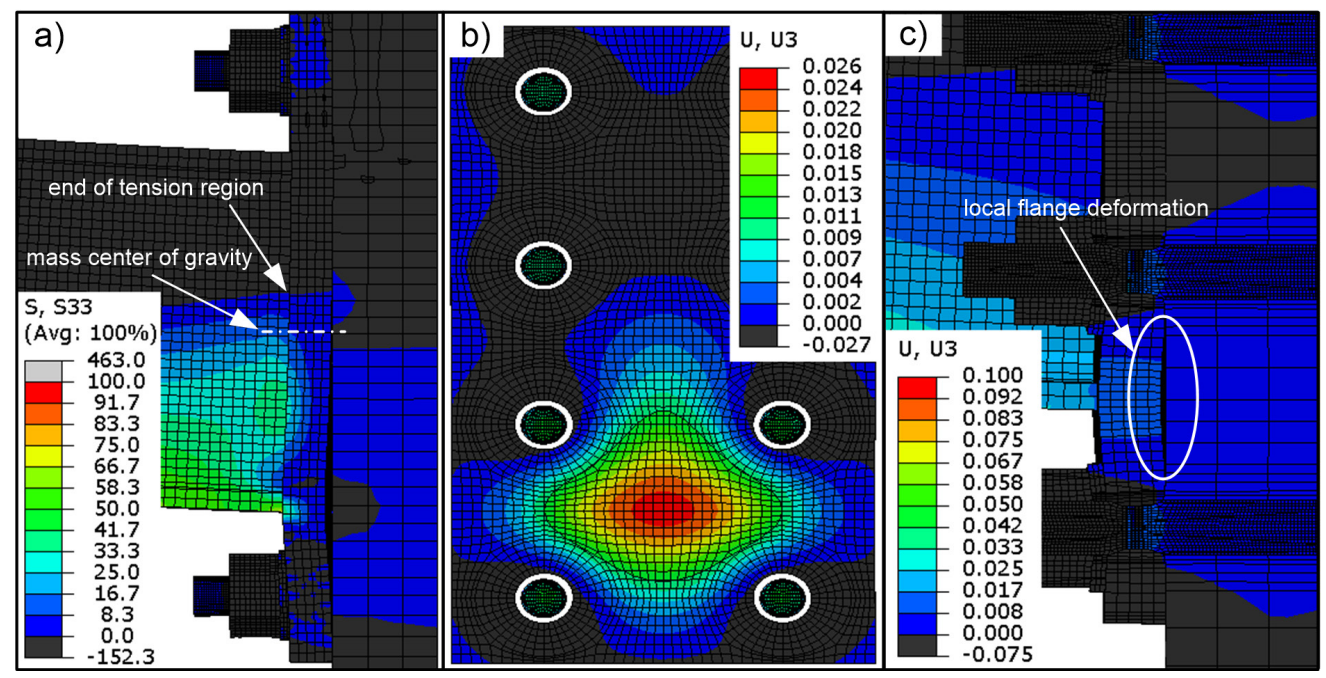

Fig. 6. Finite element analysis results for I-beam welded to the flange with a thickness of $12 \mathrm{~mm}$ :

a) stresses in a normal direction to the joint surface, b) deformation of the flange in a normal direction to the joint surface, c) deformation of the flange and bolts in a normal direction to the joint surfaces 


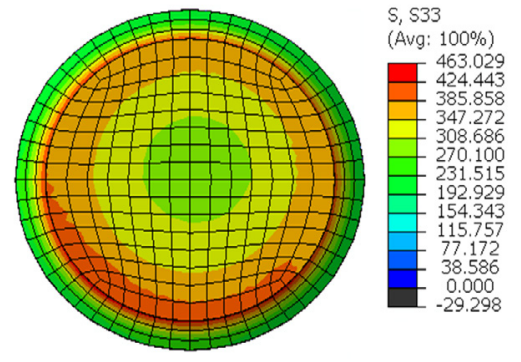

Fig. 7. Calculated stresses in a $2^{\text {nd }}$ line bolt axial direction after a $10 \mathrm{kN}$ load is applied to the end of the beam $\left(F_{O}=11163.5 \mathrm{~N}\right.$,

$$
\left.F_{A B}=605.9 \mathrm{~N}, \overline{S_{33}}=343.1 \mathrm{MPa}\right)
$$

is obvious that the bolts in the $2^{\text {nd }}$ line are subjected to the largest total operating force and not bolts in the $1 \mathrm{st}$ line as suggested by all four previous methods. This is clearly shown in Fig. 9 where the previous methods show deviations from the FE prediction for the second line of bolts, in some cases by over $100 \%$. However the new method presented here correctly identifies those bolts subjected to the highest loads. For the second line of bolts, only this method gives similar results to the FE analysis. Very similar experimental and finite element results were also gained by other researchers dealing with the pretensioned bolted endplate connections [9], [13], [16] to [21]
Based on the results it can be concluded that the analytical method presented in this paper is the most accurate. Nevertheless these results do deviate slightly from the FE analysis but these deviations are acceptable. In particular, it is very difficult to determine how much the bolts in the compressional region are relieved. Since our method assumes that bolts in the compressional region stay at the clamping level even when an additional load is applied, there are some larger deviations compared to the results of FE analysis. Since all the bolts are usually dimensioned based on the one that is loaded the most and the most loaded bolt is always in the tensional region, this deviation does not have any critical meaning as far as safety is concern.

\section{EXPERIMENTS}

In order to verify the results of the FE Analyses and the proposed analytical method, measurements of the actual forces in the bolts of bolted connections of end-plate cantilever beams were made. Measurements were performed on an IPE 120 beam welded to flanges of different thickness on each end (see Fig. 10). The flanged beam was connected to the support plate using eight pre-tensioned bolts with a clamping force of 32 $\mathrm{kN} \pm 200 \mathrm{~N}$. After pre-tensioning, an outside load of $10 \mathrm{kN}$ was applied to the beam in a vertical direction.
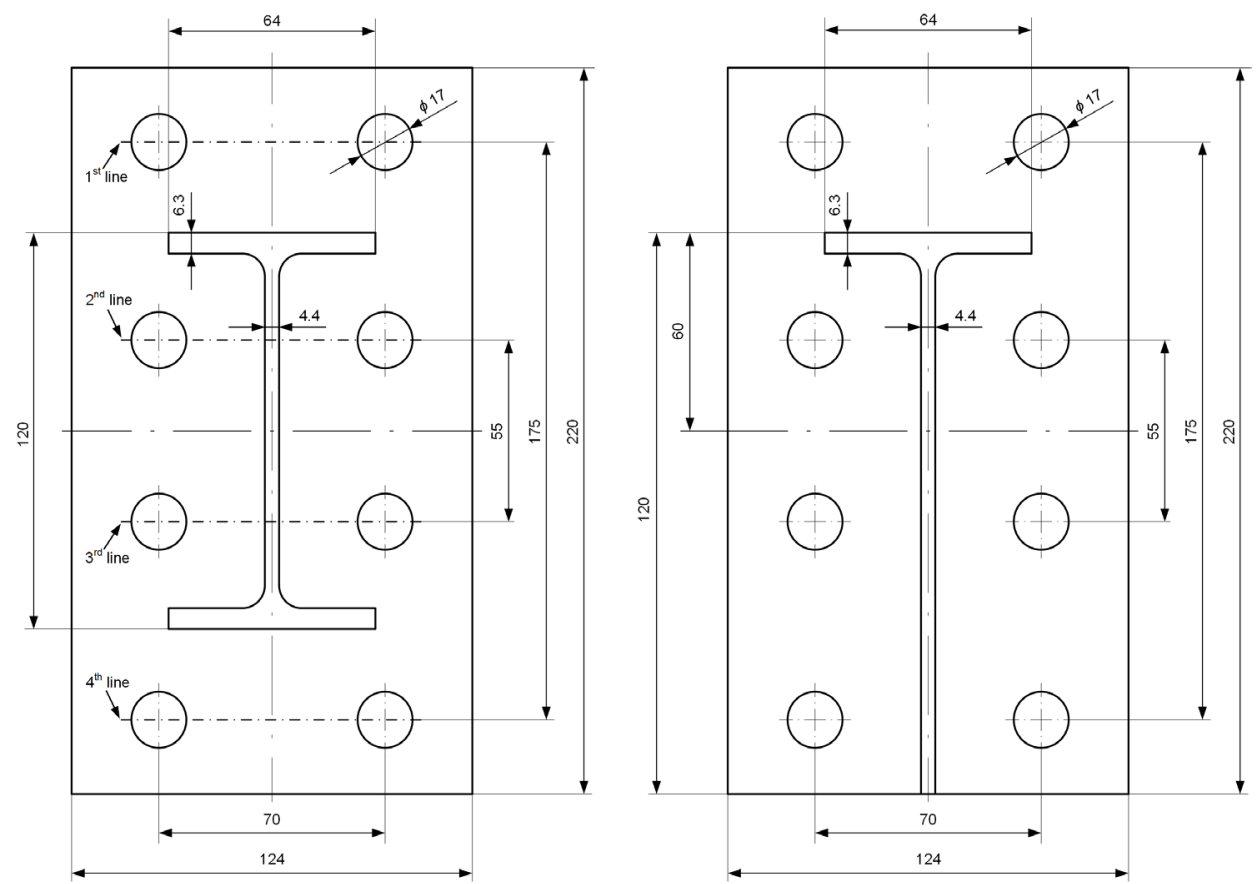

Fig. 8. Dimensions of the flanges and beams 
Table 2. Comparison of the calculated operational force on bolts by different methods

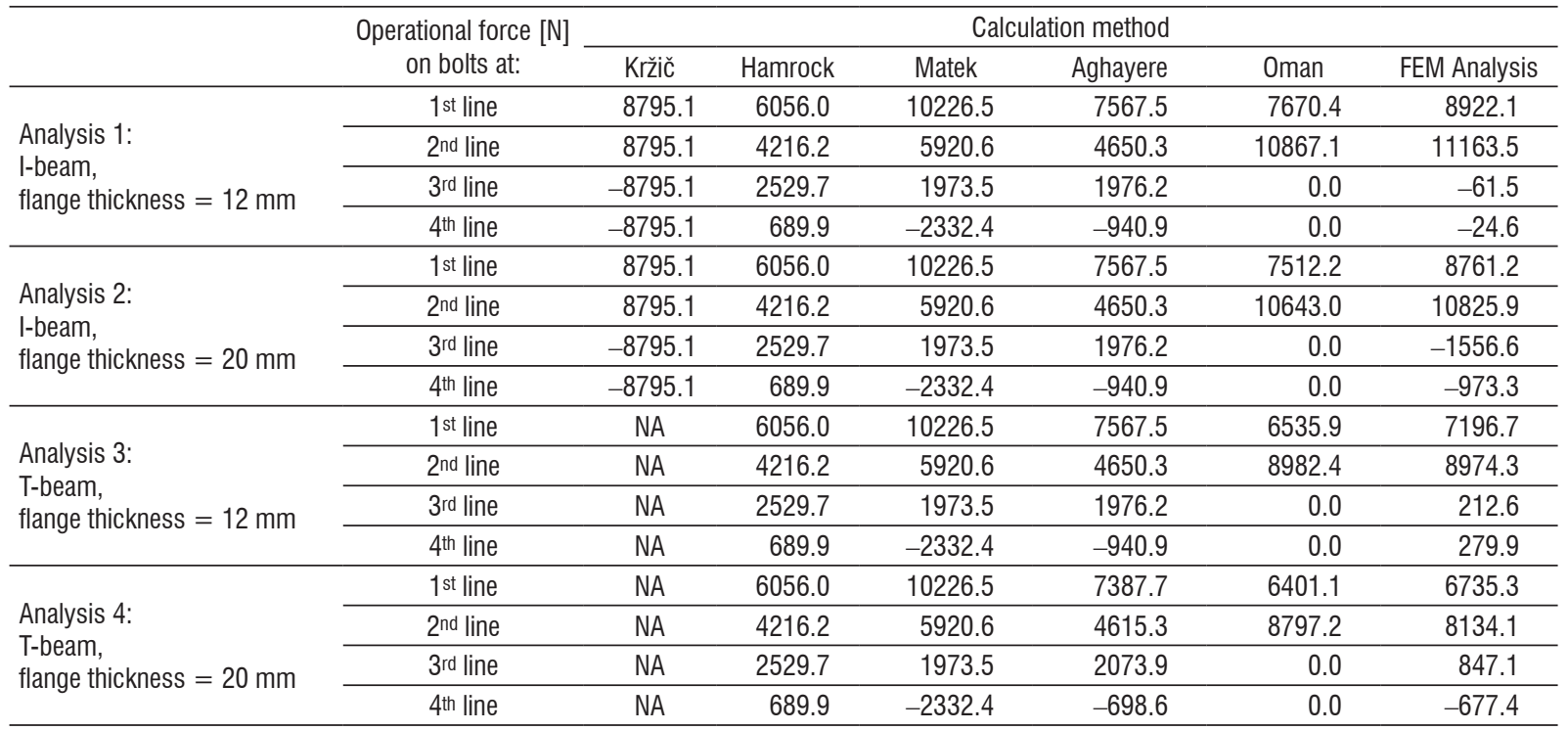
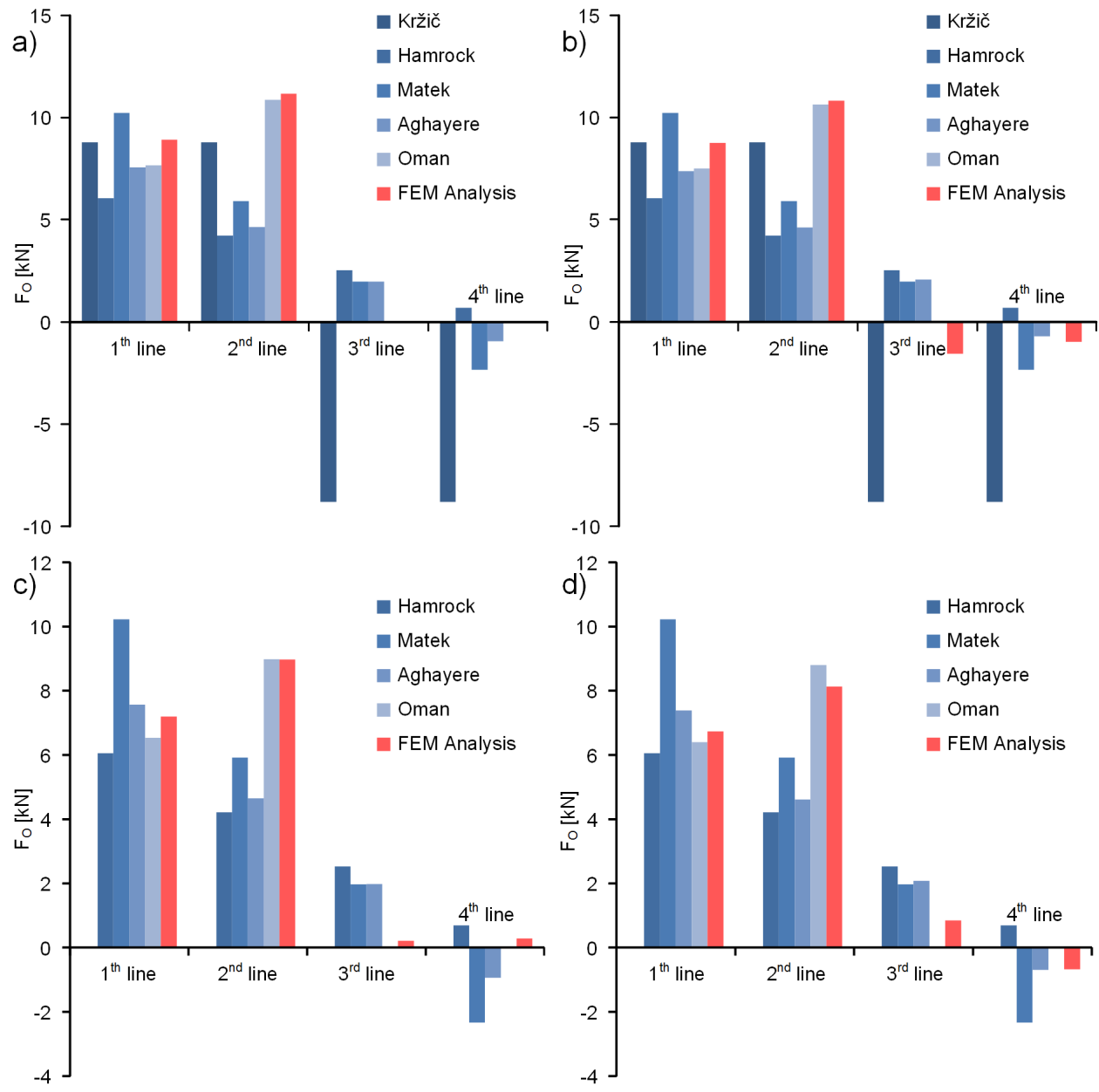

Fig. 9. Comparison of calculated operational force on bolts by different methods: a) I-beam with flange thickness of $12 \mathrm{~mm}$, b) I-beam with flange thickness of $20 \mathrm{~mm}, \mathrm{c}$ ) T-beam with flange thickness of $12 \mathrm{~mm}$, d) T-beam with flange thickness of $20 \mathrm{~mm}$ 
The load was applied in the centre of the beam flange, $400 \mathrm{~mm}$ from the support plate. A difference in force (the additional force) in each bolt before and after application of an outside vertical force was thus obtained.

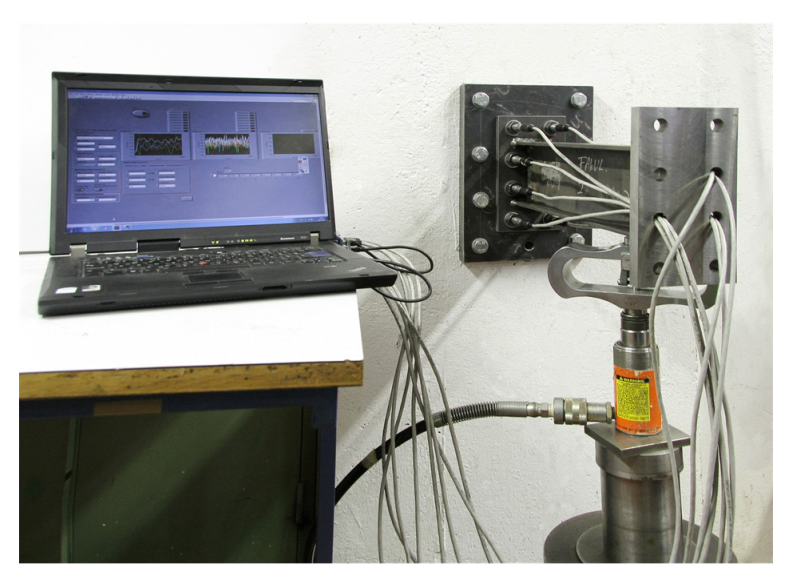

Fig. 10. Discussed cantilever beam with measurement and loading equipment

\subsection{Measuring Equipment}

Specially designed bolts equipped with strain gauges (see Fig. 11b) were used to measure the axial forces in the bolts. Strain gauges were connected in a half Wheatstone bridge circuit (see Fig. 11a) in order to compensate for bending loads [22] and [23]. Temperature was not compensated for since it was assumed that temperature does not change significantly over the duration of the measurement (the measurement lasts a few seconds). A National Instruments PXI-1033 amplifier equipped with NI PXI-4220 cards was used to perform the
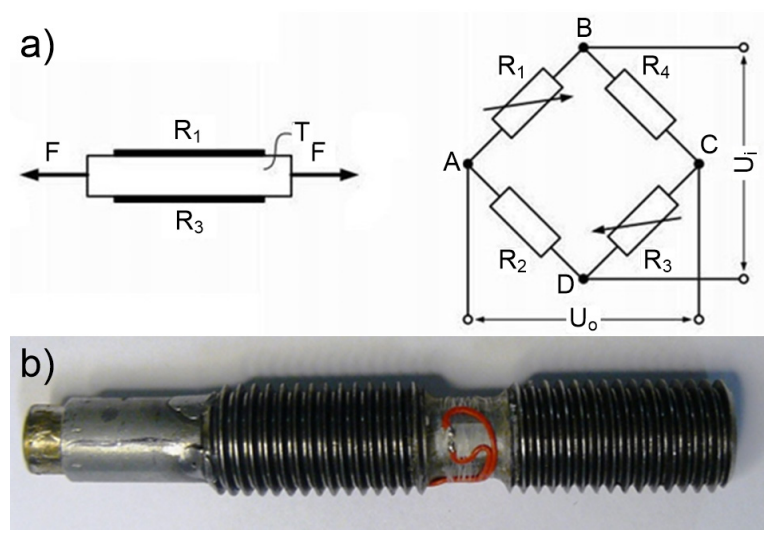

Fig. 11. Bolt equipped with strain gauges: a) strain gauge connection, b) specially designed bolt measurements. It was controlled with a specially made application in Lab View that allows on-line monitoring and data acquisition.

Measuring sensors were calibrated over a range of $0 \mathrm{kN}$ to $35 \mathrm{kN}$ using a Schenk reference device. Based on the hysteresis loop of the calibration, the accuracy of the sensors and accumulated errors during a measurement were determined [24]. The accuracy is estimated as $1 \%$ of the measuring range.

The vertical force on the beam was applied using a hydraulic valve. To measure the exact force, a load cell was installed between the hydraulic valve and the beam.

\subsection{Experimental Results}

Whilst reproducibility is poor, the overall result is very similar to the FE analysis. The additional load is mostly transferred to the bolts in the second line and a little less to the bolts in first line (see Fig. 12), while the force in the bolts in the third and fourth lines stays almost on the level of the clamping force.

During the measurements an interesting phenomenon was observed. When the additional force is applied to the beam for the first time (after pre-tensioning), the measurements of additional forces in bolts are significantly lower compared to those measurements taken when the additional force is applied for the second or more times (see Fig 12). This shows that the system somehow depresses when the force is applied for the first time and is afterwards stable.

Several conclusions have been drawn as to why the experimental results do not coincide completely with the results of FE analysis and are only poorly reproducible. Firstly, the estimated sensor accuracy is $1 \%$ of its measuring range, the range here being approximately $35 \mathrm{kN}$. On the other hand, the maximum expected additional load of the bolt is around $450 \mathrm{~N}$. Since the measured force is only slightly bigger than the estimated accuracy of $350 \mathrm{~N}$, the measured values of the force are likely to have significant errors. Secondly, FE analysis shows that the additional load of the bolts is not purely tensional but a combination of tension and bending with a ratio of around 1:1. In principle this should not be a problem since the sensors were made to compensate for bending. This compensation is correct if the strain gauges are positioned ideally on the measuring sensor. However, it is not possible to place them in the ideal position, which means the sensors are somewhat sensitive to the bending. This can be shown by applying $5 \mathrm{Nm}$ (i.e. the maximum expected value) of bending 


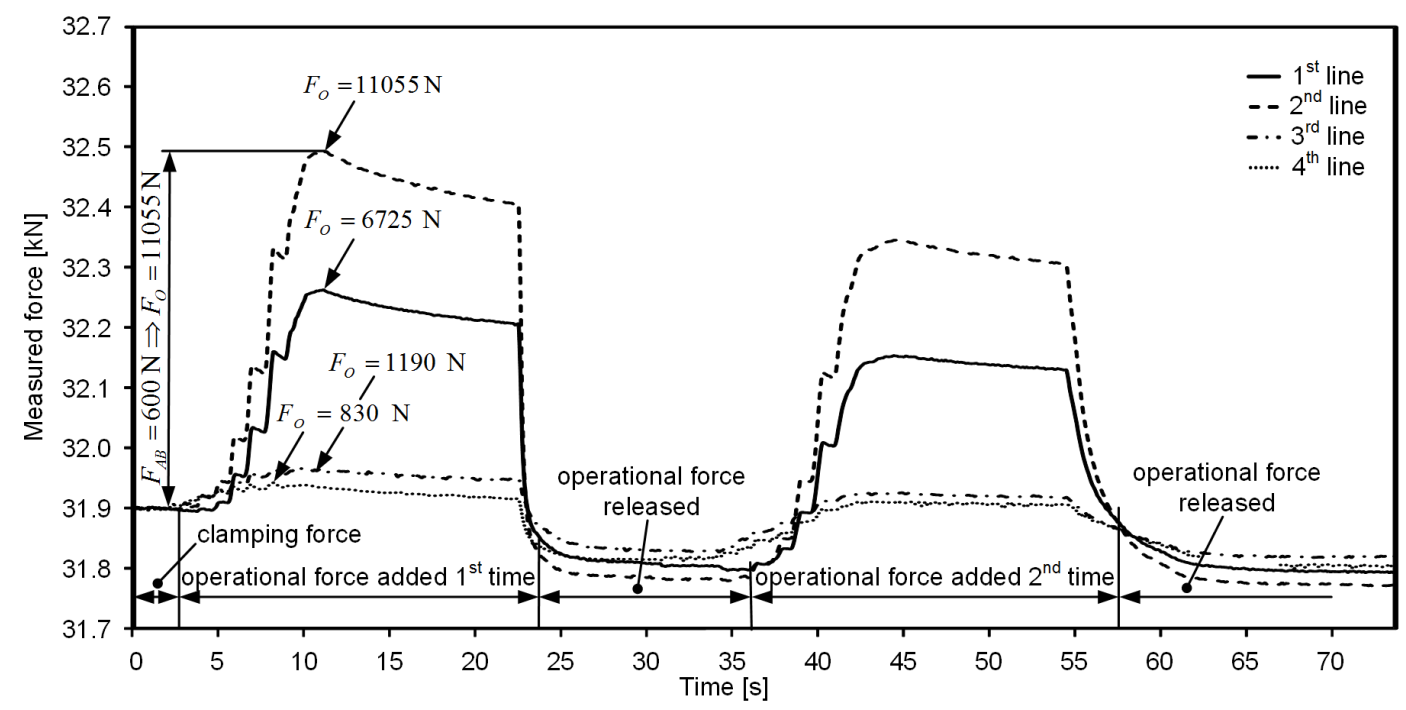

Fig. 12. Results of measured force on bolts during additional loading for flange thickness of $12 \mathrm{~mm}$ (measured force is an average of two bolts on each line)

moment on the sensors. When the bending moment is applied in a plane that crosses the strain gauge centre mark, the sensor registers $5 \mathrm{~N}$ and $80 \mathrm{~N}$ when applied perpendicular to the plane that crosses the strain gauges centre mark. Although the bolts were oriented to reduce the influence of bending moment on axial force measurements, this does contribute to errors. Based on the results and these facts it was concluded that experimental results are not very reliable and were therefore not used for a direct comparison with FE analyses and analytical methods. However, the results of the measurements are sufficiently accurate to determine which bolts take the largest share of the additional load, namely those bolts in the second line (see Fig. 12).

\section{CONCLUSIONS}

It turns out that previous methods dealing with specific prestressed bolt connections are not very accurate when calculating the operational force distribution across the bolts in the joint. Since the operational force influences the value of the sealing force and consequently the allowable tangential force at which no sliding appears in the contact, knowing the exact values of the operational forces on each bolt is very important. Therefore a new method for calculating the operating force across individual bolts for bolted connections of an end-plate cantilever beam is presented. The method is based on the following assumptions:
- the value of the clamping force is sufficient to prevent the formation of a gap between the connected surfaces around the bolts despite the action of the outside load,

- the bending stiffness of the flange is much lower than the axial stiffness of the bolts,

- the bending stiffness of the support plate is much higher than the bending stiffness of the flange.

If standards [4] and recommendations [3] for designing such joints are followed, all these assumptions are justified. Previous methods and the new method have been compared with FE analyses of such joints and the new method gives much more favourable results. Variations between the results of the FE analysis and the new method are due to numerous parameters e.g. bolt location, bolt dimension, bolt pre-tension, support plate stiffness, and geometrical ratios all of which have some influence on the actual operating force distribution but are not considered in the method as yet. Such parameters have an impact on the position of the neutral axis of the beam which separates the regions where tension and compression stresses appear. The neutral axis is shifted from its theoretical position because the bending stiffness of the flange is not the same in the tension and compression regions. This is due to complete support of the flange by the support plate in the compression region and only spotted supports by those bolts in the tension region. Deformation of the flange between the bolts is therefore allowed and is clearly visible in Fig. 6. As mentioned above this effect is not considered in 
the new method to date although it should be noted that the effects on the results would only be minor.

The study also showed that bolts in the compression region do not affect the distribution of the operating force or additional force across the bolts in the tension region, because the operating force in the compression region is not transferred to the bolts but directly to the support plate. Therefore it can be assumed that bolts in the compression region remain at the level of the initial prestressing. In reality, these bolts are slightly relieved so consequently the sealing force on these bolts is actually slightly increased. In terms of movement between the connected surfaces the calculation gives conservative results if this assumption is considered.

\section{ACKNOWLEDGMENTS}

The research described in this paper was financially supported by the Slovenian Research Agency.

\section{REFERENCES}

[1] Beg, D. (1999). Design of Steel Structures Acording to ENV 1993-1-1, 2nd ed., University of Ljubljana, Faculty of Civil and Geodetic Engineering, Ljubljana.

[2] Mott, R.L. (2006). Machine Elements in Mechanical Design, $4^{\text {th }}$ ed. in SI units. Pearson Education South Asia, Singapore.

[3] VDI 2230 Part1 (2003). Systematic Calculation of High Duty Bolted Joints, Joints with One Cylindrical Bolt. VDI - Verein Deutscher Ingenieure, Berlin.

[4] DIN 2505-1 (1990). Calculation of Flanged Joints. Deutsches Institut fur Normung E.V., Berlin.

[5] Kržič, F. (1994). Steel Structures 1. University of Ljubljana, Faculty of Architecture, Civil and Geodetic Engineering, Ljubljana. (in Slovene)

[6] Hamrock, B.J., Jacobson, B.O., Schmid, S.R. (1999). Fundamentals of Machine Elements, WCB/McGraw-Hill, Singapore.

[7] Matek, W., Muhs, D., Witte, H., Becker, M., Roloff, H. (1995). Roloff/Matek Mascinenelemente Braunschweig. Vieweg \& Sohn, Wiesbaden. (in German)

[8] Aghayere, A. Vigil, J. (2009). Structual Steel Design, A Practiceoriented Approach, Pearson education, New Jersey.

[9] Shi, G., Shi, Y., Wang, Y., Bradford, M.A. (2008). Numerical simulation of steel pretensioned bolted end-plate connections of different types and details. Engineering Structures, vol. 30, no. 10, p. 2677-2686, DOI:10.1016/j.engstruct.2008.02.013.

[10] Díaz, C., Victoria, M., Martí, P., Querin, O.M. (2011). FE model of beam-to-column extended end-plate joints. Journal of Constructional Steel Research, vol. 67, p. 1578-1590, DOI:10.1016/J.jcsr.2011.04.002.
[11] Drosopoulos, G.A., Stavroulakis, G.E., Abdalla, K.M. (2012). 3D finite element analysis of end-plate steel joints. Steel and Composite Structures, vol. 12, no. 2, p. 93-115, DOI:10.12989/scs.2012.12.2.093.

[12] Wang, M., Shi, Y., Wang, Y., Shi, G. (2013). Numerical study on seismic behaviours of steel frame end-plate connections. Journal of Constructional Steel Research, vol. 90, p. 140-152, D0l:10.1016/j.jcsr.2013.07.033.

[13] Saberi, V., Gerami, M., Kheyroddin, A. (2014). Comparison of bolted end plate and T-stub connection sensitivity to component thickness. Journal of Constructional Steel Research, vol. 98, p. 134-145, D0l:10.1016/j. jcsr.2014.02.012.

[14] El-Khoriby, S., Sakr, A.M., Khalifa, T.M., Eladly, M.M. (2017). Modeling and behaviour of beam-to-column connections under axial force and cyclic bending. Journal of Constructional Steel Research, vol. 129, p. 171-184, D0l:10.1016/j. jcsr.2016.11.006.

[15] Steinhilper, W., Sauer, B. (2012). Konstruktionselemente des Maschinenbaus 1, Springer - Verlag Berlin Heidelberg on, Berlin. (in German)

[16] Bahaari, M.R., Sherbourne, A.N. (2000). Behavior of eightbolt large capacity endplate connections. Computers \& Structures, vol. 77, no. 3, p. 315-325, D0l:10.1016/S00457949(99)00218-7.

[17] Shi, Y., Shi, G., Wang, Y. (2007). Experimental and theoretical analysis of the moment-rotation behaviour of stiffened extended end-plate connections. Journal of Constructional Steel Research, vol. 63, no. 9, p. 1279-1293, D0l:10.1016/j. jcsr.2006.11.008.

[18] Abidelah, A., Bouchair, A., Kerdal, D.E. (2012). Experimental and analytical behaviour of bolted end-plate connections with or without stiffeners. Journal of Constructional Steel Research, vol. 76, p. 13-27, D0I:10.1016/j.jcsr.2012.04.004.

[19] Dessouki, A.K., Youssef, A.H., Ibrahim, M.M. (2013). Behavior of l-beam bolted extended end-plate moment connections. Ain Shams Engineering Journal, vol. 4, p. 685-699, Dol:10.1016/j. asej.2013.03.004.

[20] Prinz, G.S., Nussbaumer, A., Borges, L., Khadka, S. (2014). Experimental testing and simulation of bolted beam-column connections having thick extended endplates and multiple bolts per row. Engineering Structures, vol. 59, p. 434-447, D0l:10.1016/j.engstruct.2013.10.042.

[21] Katula, L., Dunai, L. (2015). Experimental study on standard and innovative bolted end-plate beam-to-beam joints under bending. Steel and Composite Structures, vol. 18, no. 6, p. 1423-1450, DOI:10.12989/scs.2015.18.6.1423.

[22] Hoffmann, K. (1987). An Introduction to Measurements using Strain Gages, Hottinger Baldwin Messtechnik GmbH, Darmstadt.

[23] Hoffmann, K. (1989). Applying the Wheatstone Bridge Circuit, Hottinger Baldwin Messtechnik GmbH, Darmstadt.

[24] Holman, J.P. (2007), Experimental Methods for Engineers, $7^{\text {th }}$ ed., McGraw-Hill, Auckland. 